total eclipse visible from the British Isles. This will pass over Cornwall on August 11, 1999.

\section{European Space Marks Time}

THE much heralded European Space Conference (ESC) of Ministers in Bonn in July has now been postponed to an indefinite date in the autumn. Originally it was to have taken place "as early as possible in 1968", because much hangs on the policy decisions it is intended to take. These include the future activities of ESRO (the European Space Research Organization) and ELDO (European Launcher Development Organization) and whether these can be co-ordinated along the lines of the Causse Report (see Nature, 21\%, 1089; 1968). The European position on next year's renegotiation of the Intelsat agreement for a world network of space telecommunications and the level of European participation in various other types of application satellite were also to be discussed. It now seems probable that the European Space Conference will not only be late but limited. The British Government's decision to withdraw from ELDO at the earliest moment that is legally possible, and to have nothing to do with the Eurovision TV satellite, is likely to require so much reassessment and re-allocation of responsibilities in the short term that there will be little time left for long-term planning. This would be a mistake and an expensive one. The main trouble with joint European space projects is that ill-defined projects have been adopted too hastily and that long-term aims have been insufficiently assessed.

The decision to postpone the July meeting of the ESC in Bonn was taken at a meeting of the ESC Alternates (government officials) in Paris on May 10. From this meeting it also became clear that the British Government's analysis of the value of ELDO and the Causse Report was not shared by Britain's continental partners. The five other European members of ELDO are the ones that count. They are also members of ESRO and the effective members of CETS (Conference Européen pour Telecommunications par Satellite). All favoured the continuation of ELDO and the TV satellite as recommended by the Causse Report, and effectively rejected the British view. None of them adopted the British view of "cost effectiveness" in assessing the value of the Causse proposals. Thus they are prepared to support ELDO capital investment as an act of faith towards as yet uncertain dividends in the future. This apparently includes shouldering Britain's 27 per cent share of ELDO's costs from 1970 or so.

Meanwhile, ESRO, which in its present form Britain alone supports wholeheartedly, needs a satellite success to justify its continued existence. Its credibility has been severely dented by the recent cancellation of its major projects, the TD 1 and 2 satellites. Experimenters are well aware that simple space scientific experiments can be launched for less money and with half the trouble and delay by national programmes than by ESRO. They look therefore to ESRO only for the complex spacecraft which require a large launcher as yet beyond European scope. ESRO therefore needs a satellite success to demonstrate its ability. ESRO's first satellite was due last spring, but due to a complication of troubles a second attempt was scheduled for last Friday. Now launch of this satellite is postponed indefinitely for "technical reasons". ESRO says the delay is caused by difficulties in the third stage of the American Scout launcher. There is evidence, however, that the British-built satellite and its tape-recorder have not been working faultlessly. If the ESRO satellite misses its launch window and has to join the queue behind various American operational launches for the second time, ESRO will again have lost face.

\section{Safety in the Air}

THE standards of safety rea, hed by British airlines are significantly worse than those of airlines in the United States, or in Australia. This disquieting conclusion, already known in qualitative terms, has been put on a quantitative basis this week by a joint review by the Director of Aviation Safety and the Air Registration Board, assisted by two independent advisers (The Safety Performance of United Kingdom Airlines, HMSO, $8 s .6 d$.). There are a number of ways of measuring airline safety, none of them entirely satisfactory; but on the basis of the number of notifiable accidents per 100,000 stage flights, the United Kingdom scores $2 \cdot 62$, against $2 \cdot 03$ for France, 0.96 for Australia and 1.41 for the United States. The fatal accident record, a less reliable record because fatal accidents occur too rarely to be statistically significant, shows a similar trend. France and the United Kingdom show 0.47 and 0.43 respectively, while the United States at 0.18 and Australia at 0.09 are significantly better. Australia's performance, in particular, is startlingly good, and the report draws some lessons from it.

The review was begun after two fatal accidents involving DC 4 aircraft operated by British firms; one took place in Perpignan, the other in Stockport. But the conclusions reached by the report on the question of older aircraft are reassuring; safety records do not seem to show a decline as the aircraft ages. Such declines as there are are almost certainly caused by changes in the type of use-non-scheduled operation and smaller airlines, who use older aircraft, show worse accident records. Some aircraft seem to improve with age-the Comet 4 and the Viscount, for example, show records which have improved during the years in service. The Boeing 707 , on the other hand, after six years in service is beginning to show a worsening accident rate. One surprising conclusion is that new aircraft take a very long time to settle down to a steady accident rate. As many as two million hours of experience can elapse before the full safety potential of a new aircraft is realized-this means that if 100 aircraft are built, and each flies 3,000 hours a year, it takes six years for the "learning" period to be completed.

The report makes a number of recommendations. The most important is that the staff responsible for inspection should be brought up to full strength. Sir Frederick Brundrett, one of the independent advisers, puts it most strongly in a note in the report-"If the approved system of supervision is agreed to depend on a programme of inspections, it is quite absurd to think that this can be properly carried out without adequate staff of the right calibre". The Flight Operators Inspectorate, for example, has never been at more than half strength, and the Civil Aviation Flying Unit is 